\title{
CIUDAD E IDENTIDAD EN LA CÁTEDRA DE LA CALAVERA
}

\author{
Gregorio C. MARTÍN \\ Duquesne University
}

\section{RESUMEN}

El fin de este trabajo es estudiar cómo Margarita Torres, su autora, nos presenta en La cátedra de la calavera a una protagonista que usa los recursos de una voluntad inquebrantable para defender los derechos de su yo y la independencia de su identidad en una ciudad donde se enfrentan, en un ambiente de temor inquisitorial, los viejos postulados de la Edad Media y las nuevas ideas renacentistas.

Palabras clave: Luisa de Medrano, Isabel de Vargas, Pimentel, identidad, grupo, discriminación, inquisidor, juventud, disfraz, arca, miedo, ingenio.

\section{ABSTRACT}

The purpose of this work is to study how novelist Margarita Torres-in La cátedra de la calavera - introduces a protagonist who utilizes her unshakeable will to defend her own rights and the independence of her identity in a city where, amidst an atmosphere of inquisitorial fear, the old hypothesis of the Middle Ages and the new ideas of the Renaissance collide.

Key Words: Luisa de Medrano, Isabel de Vargas, Pimentel, identity, discrimination, inquisitor, youth, disguise, coffer, fear, ingenuity.

Al final de La cátedra de la calavera, dice uno de los protagonistas: «Como ves, puta, ninguno de nosotros es lo que parece» (Torres, 2010: 411). Esta revelación define el móvil de toda la obra, que es el difícil problema de la identidad, lo que ha llevado a Isabel de Vargas a matar a su oponente. Ella misma es una mezcla de identidades, y se disfraza de varón para fingir una más. Pero lo paradójico es que — por infinidad de circunstancias ajenas a los personajes — la 
suplantación de identidades ha llegado a ser tan compleja que ellos mismos tampoco saben quiénes son. Es decir, los personajes no son lo que parecen ser $y$, en algún caso, tampoco lo que ellos creen que son. Cada personaje de esta obra de Margarita Torres se halla atrapado en una ciudad donde las circunstancias le obligan a doblar y desdoblar su personalidad para seguir existiendo, con el deseo de llegar un día a ser lo que quiere ser. Todo sucede dentro de un marco histórico centrado en un momento de gran importancia para el país, cuando los avatares políticos habían llevado a España a un conflicto sucesorio en el que estaban en juego no sólo el futuro de la corona sino también intereses de muy distintas tendencias dentro de la sociedad española de entonces. Estos elementos conflictivos se enfrentan por existir y buscan soluciones que les permitan imponerse a las contrariedades del momento y a sus oponentes. En esa lucha por realizarse, a pesar de las limitaciones que le impone a cada personaje un entorno tan complejo y arriesgado en una ciudad donde se enfrentan bandos irreconciliables, en ese perseguir sin descanso es donde radica la importancia de esta obra.

Las ideas tienen un papel muy importante en la novela, principalmente como impulsoras de la actitud antagónica de los grupos, y la lucha incansable de Isabel es consecuencia de una idea, ya que ella no se arriesga por saber quién es, por aclarar su identidad, pues nunca duda ser Isabel de Vargas. Lo suyo es un deseo inquebrantable de afirmarse en una identidad de género, reclamar unos derechos que piensa le corresponden como ser humano, a pesar de lo que crea y defienda por tradición la sociedad en la que le ha tocado vivir. Por mantener ese derecho, Isabel se ha escapado de casa para no casarse contra su voluntad con un hombre que le ha sido asignado por decisión paterna. Entiende que esa es la costumbre, pero una mala costumbre, y cuanto antes se desarraigue, mejor. Se ha dado cuenta de que el pasado no le vale y el conformismo general la deja sola en su entorno social provinciano donde nadie pone en entredicho la norma. Si acaso su madre, pero para ella es ya muy tarde y lo único que puede hacer es aportar los medios para que la hija intente lo que en el pasado tal vez ella pensó y no pudo emprender ${ }^{1}$.

Isabel se escapa de casa con la ayuda económica de la madre, que le da joyas y dinero para subsistir por lo menos dos años en su lucha por unos derechos que, contra la opinión general, ella considera suyos y es tiempo se le concedan. Su misión es enorme. Por su magnitud, coincide con otra empresa que está siempre en el fondo de la obra: el descubrimiento de América por

1. Sabemos más adelante que la madre de Isabel sufrió y casi murió por cumplir con el deber de continuar la estirpe, que con aportar dote eran las dos misiones de la mujer en un mundo organizado según lo habían concebido los hombres que lo dirigían. 
Cristóbal Colón. Tampoco él contaba con el apoyo necesario para poner en práctica una idea que perseguía reemplazar un axioma con su homólogo, non plus ultra por plus ultra, y, al fin, consiguió también la ayuda de una mujer, Isabel la Católica, varias veces mencionada en la obra como la pionera en España de este movimiento de reivindicación femenina. No es, pues, coincidencia que también en la novela sea otra Isabel la que rompa las normas y comience con el apoyo de otra mujer: su madre. Precisamente el desespero y el miedo que producía a la madre de Isabel aquella costumbre de hacer a la mujer responsable exclusiva de continuar la estirpe, dio lugar a uno de los misterios mejor plasmados en esta obra, que terminará sin que lo descubra la misma Isabel, quien, por otro lado, había decidido cortar con el pasado y preocuparse sólo de labrar su porvenir.

Hay un momento al principio de la novela cuando Isabel, agotada por el largo viaje tras su fuga de la casa paterna, descansa al lado de un arroyo bajo una lluvia torrencial. Tiene que elegir qué camino tomar, y decide ponerse en manos de la suerte tirando al aire una moneda «del tiempo de los moros» (Torres, 2010: 26) que le había dado su padre cuando era niña. Pero la moneda no soluciona nada porque cae de canto. La joven le da una patada y aquel recuerdo se hunde en el arroyo de Mozárbez. Es el símbolo de un pasado que desaparece en la corriente de agua turbia porque no tiene valor en el presente y a su dueña no le sirve. Como la corriente del río, la vida está en constante devenir y hay que tener nuevas ideas para los nuevos tiempos porque el tino no consiste en aferrarse al pasado, sino en asimilar el presente para preparar el porvenir. Isabel, empapada por la lluvia, despierta así a una nueva vida cuyo futuro no está escrito y sólo podrá decidirlo ella. Ese deseo de autodefinirse imponiendo la propia voluntad fue decisivo para que abandonara a la familia para no pasar el resto de su vida con alguien que no conocía y por el que no sentía ningún afecto, «... un hombre corto de vista, labios finos, cuello de pollo, escuálidos cabellos, enclenque, engreído patán con pretensiones de señor. Rala conversación de teólogo batueco grandilocuente y fatuo» (Torres, 2010: 39). En lugar de sacrificar su futuro para vivir con aquella «estampa de otro tiempo»((Torres, 2010: 26), como la moneda que ahora se llevó el agua, Isabel se escapó de casa para enfrentar el destino con una afirmación indomable de la propia identidad.

Sola, por primera vez fuera de su casa, en un espacio abierto que desconoce, con una naturaleza hostil y bajo circunstancias adversas, Isabel de Vargas muestra ya un carácter fuerte que será constante en esa lucha que ha iniciado en defensa de su yo femenino. Llega a la ciudad, «tan lejana del mundo que conocía» (Torres, 2010: 53), y tampoco allí se siente intimidada 
por el entorno ciudadano que le es igualmente ignoto. Lejos de sentirse agobiada por la cantidad y diversidad de habitantes, Isabel descubre, aprende y disfruta. Se siente libre, por primera vez libre. A lo largo de la novela, estos espacios van a limitarse cada vez más según exista mayor o menor riesgo para la libertad, poniendo a prueba la entereza de la protagonista, hasta que se decida el logro o fracaso de su lucha y, por lo tanto, la conquista o pérdida de sus objetivos. Esto sucederá cuando se dirima en una contienda legal qué idea y qué grupo saldrá victorioso

La joven va a Salamanca donde vive su prima Luisa de Medrano, otra peregrina que reclama un derecho justo. Las piedras de la ciudad han asumido la identidad de sus ciudadanos. Son testigos de la Historia, la única verdad en este juego de identidades, y muestran el rango de sus hijos en los escudos incrustados en ellas. Y por las piedras descubre Isabel el abolengo de su futuro amigo, por más que él trate de parecer todo lo contrario. La joven persigue liberarse de un pasado que la condena a someter su voluntad porque así lo ordena un código de normas anquilosadas de un mundo feudal. Luisa de Medrano aspira conseguir el derecho a integrarse en una profesión dominada por ideas discriminatorias que el nuevo saber renacentista pone en entredicho. En los dos casos, sus oponentes son los mismos: las ideas de los hombres. Se trata, por lo tanto, de un conflicto de género, donde uno, el femenino, reclama lo suyo, mientras que el otro, el masculino, tiene y quiere lo de los dos. La solución no es fácil porque están en juego intereses de entidades poderosas que defienden una postura con la misma contundencia que condenan la otra.

España estaba entonces «todavía en formación, temerosa de novedades, cobarde en avances, oscura en pensamiento, hija de ochocientos años de lucha con los moros» (Torres, 2010: 31). Y Salamanca era, según dice Antonio Pimentel, «la capital del saber de estos reinos, hija mimada de monarcas, refugio de clérigos, estudiantes y truhanes» (Torres, 2010: 69), donde «todo tenía un precio» (Torres, 2010: 74). Pero el inquisidor Juan Ruiz del Monte tenía una imagen bien distinta. Para él la ciudad del Tormes era «nido de heterodoxos, disconformes, sectarios, foco de vientos llegados de Europa, hogar de conversos de torcidas costumbres, una de las pústulas que debían sanarse en el enfermo cuerpo del reino» (Torres, 2010: 103). Para unos, una joya y, para otros, un centro de corrupción. Los extremos no se tocan y era muy difícil conciliar opiniones. Los ciudadanos transitan por las calles, serán testigos de duelos, borracheras y pendencias estudiantiles, pero sólo como grupo, y así se mencionan directa o indirectamente en la novela.: «la vida corría a borbotones por la ciudad» (Torres, 2010: 54), «era fama en Salamanca» (Torres, 2010: 155), «la tranquilidad de los vecinos», «la paz de Salamanca» 
(Torres, 2010: 197), «antes de que toda la ciudad sepa» (Torres, 2010: 203), «toda Salamanca sabía «que no le sentaban bien las madrugadas a Laurentino Fresno (Torres, 2010: 271), «Salamanca entera se recogía en casas y mesones para comer» (Torres, 2010:285), y en grupo presencian el combate de Isabel con Laurentino Fresno (Torres, 2010: 299), de cuya muerte acusará después el inquisidor a la joven porque «todo Salamanca [lo] conoce» (Torres, 2010: 352). Cuando se juzgue a Luisa de Medrano y a Isabel de Vargas, a pesar de ser Luisa hija de una de las familias salmantinas más ilustres, nadie del pueblo llano podrá presenciar el juicio en el salón universitario, con las puertas selladas por orden del rector.

Como Isabel, otros han acudido a Salamanca persiguiendo cada cual lo suyo, agobiados u obligados por su identidad. La ciudad recibe a todos y los engulle dentro de sus murallas, segura de sí misma y de su lucha con el tiempo, que es siempre quien termina con las ambiciones de los hombres. Allí está Antonio Pimentel, joven inteligente, a quien le es negado el derecho de graduarse en medicina a pesar de que su mucho saber y buenos servicios son indispensables en el hospital. Es hijo bastardo del almirante de Castilla, y esa realidad, sobre la que él no tuvo control ni puede cambiar ahora, vale para que se le niegue el valor de su inteligencia. Antonio lleva en Salamanca una vida desarraigada y libertina porque no le está permitido graduarse ni poner legalmente en práctica sus conocimientos. En su fuga, Isabel se refugia en Salamanca para librarse de una condena (Torres, 2010: 43), como ella califica acertadamente que las mujeres sólo se consideren útiles para aportar dotes y asegurar la estirpe. Razones de estirpe condenan también a Antonio por ser bastardo. El caso de Luisa de Medrano es diferente, como ella misma dice (Torres, 2010: 43), pero tiene idénticas raíces y los mismos ejecutores: los hombres. Después de haber sido rechazada públicamente por los varones de la universidad para ocupar la cátedra de Nebrija, la aceptan ahora sólo porque su padre impartió clases allí, pero, cuando el maestro regrese a la cátedra, sabe que la denigrarán por haber osado ejercer una profesión reservada para los hombres.

Torres hilvana con maestría los numerosos misterios que surgen conforme avanza la narración. Para ayudarse a navegar por ese turbulento dédalo, los personajes se agrupan por parejas porque sus necesidades son idénticas y los acercan. La discriminación que, por ser mujer, sufre Luisa de Medrano como profesora, la lleva a unirse a su prima Isabel, que no puede asistir a las clases en la universidad por la misma razón. Luisa, cuando falsifica los documentos para que Isabel de Vargas se transforme en el bachiller Pedro Bravo, demuestra a los hombres que engaña que el mérito reside en el talento, no 
en el género de la persona. Isabel se une primero con Antonio por recomendación de Luisa para ocultar su identidad y, después, porque son dos almas gemelas que luchan por lograr un puesto en la vida por méritos propios. Él era «Un náufrago del destino, igual que ella» (Torres, 2010: 57). El rector y el maestrescuela — converso uno y judío el otro- se unen para defender la independencia de la universidad frente a la Inquisición. Juan Ruiz del Monte y Álvaro de San Emiliano se unen porque así conviene a sus particulares ambiciones. Ninguno persigue un objetivo justo, sino satisfacer la codicia propia. Es la pareja menos homogénea y, aunque parecen los más fuertes, terminarán destrozándose mutuamente. Los grandes, el rey Fernando y el cardenal Cisneros, apenas si intervienen, aunque por su poder se hacen sentir durante toda la novela. El Rey representa e infunde esperanza, lo que podría suceder; mientras que el Cardenal es el agobio, la intransigencia e infunde miedo, lo que nadie quiere que suceda.

La Universidad de Salamanca, a pesar de sus limitaciones, es la nueva estrella que quiere brillar con luz propia porque sus estatutos le otorgan una independencia que le permite romper códigos y normas del pasado e instaurar las propias. Es aquí donde surge el conflicto con la Iglesia. En esta lucha entre autonomía y control cada bando usa sus armas: Cisneros, la Inquisición; la Universidad, la juventud. Ha sido la Universidad la que dio el gran salto a la modernidad olvidando normas intocables, que ahora Cisneros considera fuente de toda posible corrupción venidera. Y nada era más importante entonces para la Iglesia que la función de la mujer en la sociedad conforme la define el inquisidor Juan Ruiz del Monte: «compete al hombre el gobierno y regimiento de toda materia y a la mujer la honra del hogar y su supeditación total al marido» (Torres, 2010: 359) ${ }^{2}$. Por este axioma del inquisidor, las mujeres estaban condenadas al infierno, como dice Luisa de Medrano (Torres, 2010: 42). De ahí que el único modo de evitar consumirse en sus llamas sea por vía de varón. Pero esto requiere una naturaleza fuerte y decidida, dispuesta a asumir riesgos. Las dos primas nos sirven de ejemplo.

Luisa de Medrano es estudiosa y reflexiva. Ella preferiría pasar la vida dedicada al estudio, pero las circunstancias no la dejan. A pesar de su excelente preparación académica, de contar con la protección de Nebrija y de los dos hombres más poderosos de la universidad, siempre se encuentra incómoda. Tampoco le ayuda todo lo que representa su familia en la ciudad. Sabe que no tiene futuro porque perderá la cátedra tan pronto regrese Nebrija. Sin

2. Para Cisneros, la mujer es débil por su condición femenina, y debe obedecer lo que él considera un mandato divino: «Las mujeres deberían conformarse con el papel que se les asignó desde la Creación: rezar, cuidar del esposo y procrear»(Torres, 20101: 107). 
embargo, no toma ninguna iniciativa. Actúa para satisfacer a otros o cuando se ve obligada a defenderse. Si falsifica diplomas o expedientes académicos es porque Isabel los necesita para ingresar en la universidad y la obliga a hacerlo; si responde a Ruiz del Monte cuando éste quiere registrarle la casa y, después, en la cárcel a los alguaciles del corregidor es porque ya no tiene otra alternativa, pero nunca emprende nada contra aquél aunque ya le ha advertido su tío, el rector Maldonado, que el inquisidor es su gran enemigo y se valdrá de ella para conspirar contra la independencia de la universidad. A Luisa le ha tocado vivir en un mundo que no es el suyo, puesto que la universidad no era el centro de concentración, quietud y estudio que a ella le gustaría. Isabel capta pronto el antagonismo entre la universidad y su prima:

Cuanto más conocía el mundo universitario, Isabel más admiraba el talento de su prima. No sólo se trataba de un mundo de hombres, sino de una fortaleza cerrada a toda persona ajena a los usos, intrigas, manejos torticeros e intereses varios para ocupar cátedras e impartir enseñanzas. Rara vez los mejores ocupaban los puestos que merecían, al carecer de padrinazgo o fuerza de linaje (Torres, 2010: 54).

Y sin embargo Luisa pinta con discreción y acierto en las páginas de la novela la imagen de lo que pasa en la universidad. A su clase de Retórica asistía más de un centenar de varones, ninguna mujer, que buscaban «medrar y no saber»; se conformaban con "superar la asignatura» y disfrutar durante el curso tentando a la profesora para probar los límites de su prudencia, «el aguante de una mujer» (Torres, 2010: 235). Si conoce bien la situación de la mujer en la universidad, tampoco ignora la tiranía a que la somete la vida, la triste realidad, como ella dice cuando Isabel le cuenta las razones de su fuga:

Aquellas duras palabras correspondían a la triste realidad de muchas mujeres. Debían aceptar el esposo que eligieran los cabezas de sus linajes, sus opiniones poco importaban. Desde que nacían se convertían en moneda con la que negociar en beneficio de la estirpe, del honor de su apellido, de la red de parentesco y poder que agrupaba, que defendía la sangre que los diferenciaba del resto. Solo servían para apalabrar alianzas, aportar dotes y herencias y regalarle progenie al marido, pleno dueño de sus cuerpos, celoso requeridor de sus propias necesidades (Torres, 2010: 40).

En una situación tan precaria - que Luisa percibe cada día en las aulas cuando estudiantes brabucones, adiestrados por el bando enemigo, intentan ridiculizar sus ideas por el mero hecho de ser mujer- es necesario actuar para anticiparse a las circunstancias, como quiere Isabel, pero Luisa no lo hace y recomienda rendirse: «¡Maldita sea! ¡Ya basta! ¡Eres una mujer! ¿Acaso no lo entiendes? Deja de luchar contra el mundo, porque ninguna de nosotras podrá cambiar lo que somos» (Torres, 2010: 55). La indecisión de Luisa la 
privará del hombre que ama, que, en su caso, no tendría oposición paterna por razones de rango porque la corteja un sobrino del almirante de Castilla. Falta de autoridad, de fuerza y de apoyo del profesorado, Luisa es el primer destello de una luz de esperanza, de un sueño, que tardará en hacerse realidad.

Isabel es todo lo opuesto, un torbellino al lado del remanso. Prefiere la acción a la pasividad, la valentía al miedo, acometer a defenderse, ser astuta a ser ingenua y rebelde a ser sumisa. Como hará más tarde un conquistador, Isabel quema las naves que representan el pasado y se entrega en cuerpo y espíritu a labrarse el futuro que desea ${ }^{3}$. Para ella no hay retorno, sólo un rumbo hacia adelante para triunfar en un ambiente que le es totalmente desconocido, o perecer en el intento. Es otra vez Luisa quien describe con agudeza a su prima: «Parecías un joven hidalgo recién llegado a la ciudad, dispuesto a devorar la vida o a ser engullido por ella» (Torres, 2010: 43). Isabel rompe con su pasado, convence a su prima para que falsifique el expediente académico que le abre las puertas de las aulas universitarias, busca a Antonio Pimentel en un prostíbulo aunque tenga que arriesgar su vida, salva con astucia a su prima Luisa de las garras del inquisidor cuando éste intenta registrar la casa, lucha con el matón Laurentino Fresno, Capador, y obtiene de él la confesión que necesita sin importarle que el criminal está a punto de morir. También es Isabel quien da al final el golpe de gracia a Gorgonia y a San Emiliano, las dos cabezas de la Hermandad de la Garduña, ante los ojos atónitos de Antonio, sin considerar por un momento que ya están heridos de muerte. Cuando se entera de que Nebrija va a regresar a la cátedra y el rey manda que ella y Antonio se vayan a la corte, Isabel comprende que para su prima aquello sería «el final de sus sueños» (Torres, 2010: 406), y pide al joven - y consigue- llevarse a Luisa con ellos para que siga buscando su camino. Ambas se complementaban y en aquella contienda de identidades eran una amalgama perfecta de acción y discreción.

Sólo era posible acceder a las aulas como varón. Pero Isabel, en sus correrías por las calles, había observado con agudeza que la ciudad era una conchabanza de frailes, lavanderas, sirvientas, comerciantes, artesanos, vendedores de verduras, taberneros, teólogos, juristas, médicos y un sin fin de personajes que se ocupaban en toda clase de oficios, no siendo los menos pícaros y prostitutas. En este mundo tan complejo convivían la verdad y la mentira, la apariencia y la realidad, truhanes y santos, héroes y rufianes, un contubernio donde cada cual iba a lo suyo, todo era posible y nada asombraba

3. Al final, en uno de los giros más ingeniosos de la novela, es el joven Hernán Cortés quien se hace con el mapa de Colón que contiene el secreto de las tierras de América. 
a nadie. La misma universidad estaba poblada de clérigos que difamaban a su prima mientras ellos vivían en la impudicia y eran asiduos visitantes de prostíbulos, varones que se llamaban estudiantes y dilapidaban el tiempo en borracheras, intrigas y pendencias, profesores que no enseñaban y otorgaban injustamente títulos universitarios —ateniéndose a consideraciones de estirpe que nada tenían que ver con méritos académicos-, y empleados que robaban sin escrúpulos.

Gracias a Luisa había conocido las entrañas académicas de la universidad [...]. También la influencia de algunos catedráticos frente a otros, especialmente si su linaje había ofrecido sus servicios durante generaciones, pues no era infrecuente que los padres se las arreglaran para dejar el cargo a los hijos o los yernos, ni que un buen padrino allanara el sendero para ocupar tan destacado sillón con total desparpajo académico (Torres, 2010: 87).

Un gran disfraz donde nada era lo que parecía. Hasta el mismo Antonio Pimentel tampoco es lo que parece. Por lo tanto, una máscara más no podía sorprender a nadie porque todo era ya un sortilegio. Y si sólo se puede entrar en la universidad por vía de varón, Isabel se convertirá en Pedro Bravo, bachiller graduado en Bolonia gracias a la destreza caligráfica de su prima. La farsa es doble, y es de nuevo Luisa quien define sutilmente la situación de las dos, incluso antes de suplantar identidades: «No te inquietes. Ambas, de una manera u otra, parecemos hombres: tú por las ropas que portas, yo por ejercer un oficio propio de varones. Estamos condenadas al infierno. Al menos nos haremos compañía» (Torres, 2010: 42). Era lo máximo a lo que podían aspirar, a parecerse, pero no a ser tratadas de la misma manera. Por otro lado, si fingir o interpretar una identidad las forzaba a tener que parecer hombres para que les otorgaran los derechos de otra, también las ponía en riesgo constante de ser descubiertas y condenadas por ellos, pues eran los hombres quienes habían establecido las normas. Al mismo tiempo, ellos podían fingir infinidad de identidades sin ser vituperados por nadie. El mismo rector Maldonado era converso, y el maestrescuela, que era judío, había tomado los hábitos de clérigo porque así le convenía al rey Fernando, que lo trajo de Portugal para que le ayudara como espía. Isabel podrá obtener también su título universitario algún día, pero sólo cuando a los hombres les convenga.

La duplicidad masculina queda patente en el trato que recibe otra clase de mujeres. Las que viven en el barrio de la Mancebía o en el prostíbulo de las Ocho Beatitudes gozan de más respeto que Luisa de Medrano, pues así les conviene a los hombres porque satisfacen sus pasiones. Allí acudían con asiduidad profesores, alumnos y clérigos como el dominico fray Bartolomé, cartógrafo, uno de los mejores clientes de las Ocho Beatitudes, cuyos indiscretos 
monólogos revelaron a las ocupantes dónde se encontraba el arca de los reyes con los mapas de Colón, lo que le cuesta la vida al principio de la novela. Este crimen da comienzo a una serie de muertes que no parecen afectar a nadie por la pérdida de vidas, sino por la desaparición de los documentos del arca, los mapas. El rector, responsable de la custodia del arca que le había encomendado el rey, organiza con el maestrescuela la forma de recuperarla, y nombran a Antonio Pimentel y a Pedro Bravo (antes Isabel de Vargas) para tal cometido. Pero los jóvenes siempre llegan tarde. Alguien se les adelanta y roba los documentos o mata a quienes podían aportar datos sobre su paradero.

El bando religioso de Cisneros - dirigido por su testaferro el inquisidor Juan Ruiz del Monte y el incondicional de éste, Álvaro de San Emilianotampoco presta gran interés a los muertos, hasta que descubre la causa de su violento fin. Esto le permitirá acusar al rector Maldonado de negligencia por el robo del arca, pero Cisneros le había advertido que actuara con muchísimo cuidado porque Maldonado de Talavera ocupaba su cargo por méritos propios y era consejero de reyes y príncipes. Había que buscar otro camino a través de Luisa de Medrano, a quien Maldonado — sin tomar en cuenta su «débil» condición de mujer (Torres, 2010: 106-07)— había apoyado cuando la propuso Nebrija para la cátedra. Pero los días pasaban y Luisa, en extremo celosa de su cargo, no cometía ningún desliz advertida por el rector: «Te quiere a ti. La única persona que en estos momentos le interesa eres tú, o, para ser más precisos, representas el camino para cercenar el mío y estrangular la universidad hasta que se pliegue a sus reformas» (Torres, 2010: 50).

Ruiz del Monte se desesperaba y, azuzado por el deseo de impresionar a su señor, la espera por cazar a la profesora lo tenía obsesionado. Lo irónico es que está también obsesionado con capturar a una joven que humilló a un sobrino suyo cuando escapó de la casa de sus padres para no casarse con él. El inquisidor no lo sabe, pero esa joven es Pedro Bravo. Sospecha que se encuentra en la ciudad porque le han dicho sus espías que Isabel de Vargas era pariente de Luisa y una mujer había estado en casa de la profesora, pero desapareció luego sin dejar rastro. Se había prometido encerrar a Isabel de Vargas en la cárcel de la Inquisición, pero la vanidad por impresionar a Cisneros le juega una mala pasada cuando antepone pasión a razón y pospone la búsqueda de Isabel para cumplir la encomienda del regente. Él, experto en descifrar identidades, tiene a Isabel de Vargas entre las manos y no descubre la farsa porque le engaña el ingenio de la joven, que sabe contestar con sutileza las preguntas del inquisidor y hasta se atreve a advertirle que ella es intocable por la influencia familiar cerca del mismo Papa. El episodio resulta irónico porque Ruiz del Monte tiene la presa que busca y la deja escapar. Torres resalta así la fuerza y valor de la 
voluntad femenina, pues era necesario un tremendo esfuerzo para superar con serenidad el miedo que a todos infundía el inquisidor. Es un encuentro simbólico que anticipa la causa de la caída de Ruiz del Monte, un hombre que no es capaz de controlar sus emociones. Cuando hay que dirimir contiendas o diferencias de opiniones en debate público, aportando pruebas y testigos, el inquisidor no puede competir. Juan del Monte es bueno para atemorizar, pero no para convencer.

El episodio del encuentro de Pedro Bravo con Juan del Monte describe el carácter firme de la joven y la urgencia que tiene por resolver su vida. Una prisa de la que no está dispuesta a permitir que la distraiga nada ni nadie. El encuentro con el inquisidor es consecuencia de esa prisa, y nos lo dice la autora: «Literalmente lo embistió con todas sus fuerzas, tal era la prisa que llevaba, y Ruiz del Monte cayó al suelo por su culpa, sin que pudiera evitarlo» (Torres, 2010: 123). Esta embestida de Isabel, aquí sin intención, es símbolo de lo que vendrá después, porque ella tiene prisa por lograr sus objetivos y no van a detenerla los métodos de Ruiz del Monte que persiguen humillar con amenazas y miedo. Isabel, si las circunstancias lo requieren, no va a dudar enfrentarse a aquel hombre que insulta sin motivos, acusa sin pruebas y se vale de métodos indignos a su profesado estado religioso. La embestida, ahora sin intención, augura el dicho popular de agarrar el toro por los cuernos y humillarlo con astucia, no con violencia. Y lo hace acto seguido tras controlar el pánico que le infunde el inquisidor, porque así es la vida: hay que dominar primero nuestros propios temores para vencer después los ataques ajenos.

No será la caída del inquisidor la única vez que el ingenio venza al miedo. Cuando Ruiz del Monte quiere registrar la casa de Luisa y detenerla, Isabel lo engaña de nuevo. Contra el consejo de Antonio que - herido- se esconde en el establo, sale en defensa de su prima, no para disculparse, sino para pedir explicaciones por el allanamiento de morada ( ¿¿Cómo os atrevéis?»), y responde a la amenaza del inquisidor con la suya, usando la mentira de su primer encuentro para recordarle que tiene parientes en Roma (Torres, 2010: 228).

La palabra miedo se usa más de sesenta veces en la obra. Miedo tiene Isabel de que se descubra su verdadera identidad; Luisa tiene miedo de perder su trabajo; el rector, la independencia de la universidad; el maestrescuela, la esperanza de algo muy personal que le impulsó a pactar con el rey Fernando; Antonio, su futuro, y todos tienen miedo del inquisidor. El mismo Ruiz del Monte tiene miedo de perder el favor de Cisneros, y al final su miedo se convierte en pánico ante la muerte, que le llega a manos de otra gran mentira que tampoco supo descubrir a pesar de tenerla siempre a su lado. 
Razones de género y estirpe hacen que la identidad se una con la mentira y el miedo. Salvo permanecer a la defensiva, nada puede hacer Luisa para ocultar su identidad femenina en una ciudad donde todo el mundo la conoce, lo que supone que el espacio urbano de Salamanca tiene unos límites, ya marcados físicamente por la muralla. La situación de Luisa es la más triste porque, en un mundo de rufianes, a ella sólo le está permitido ser íntegra. No es lo mismo con Isabel, pues su anonimato le permite cambiar de identidad por razones académicas y volver a recuperarla cuando mejor le convenga. Su valor y su ingenio le bastan para todo lo demás. La farsa de Ruiz del Monte es moral. Se considera extremadamente celoso en la defensa de los principios de su fe y llama «Salomé impúdica» a Luisa de Medrano, a lo que la profesora de Retórica le da una digna respuesta que resultará premonitoria: «Para que yo fuera Salomé, fray Juan, vuesa paternidad habría de llamarse Herodes y ambos buscar la cabeza de San Juan Bautista [...]. Por lo que he visto, acostumbráis dejar a vuestro paso pisadas de sangre. Cuidad que el demonio no encuentre vuestro rastro, o a quien daréis cuentas no será a mí, sino al Todopoderoso» (Torres, 2010: 121). Pero Ruiz del Monte ha antepuesto su ambición a su religión, y aquella le ciega.

Cuando el matón Laurentino Fresno, Capador, está a punto de morir porque ha sido envenenado con arsénico en el prostíbulo de las Ocho Beatitudes, lo enfrenta Isabel en una de las callejuelas de la ciudad y, después de obtener la información que necesita, lo abandona porque su caso no tiene remedio y vienen los alguaciles de la guardia. Capador les dice que Pedro Bravo es el culpable de su próxima muerte. Antonio salva a Isabel de los alguaciles y la lleva a casa de Luisa donde momentos después las arresta el corregidor y las encierra en la cárcel. Este episodio de la lucha entre Capador y Pedro Bravo es importante para que juzguemos después la maldad del inquisidor y su concepto de la justicia cuando se celebre el juicio contra Luisa y su prima. La laucha del matón con el bachiller la presencian los ciudadanos tras los cristales de sus ventanas, pero ninguno de estos testigos visuales es requerido por el inquisidor para que corrobore sus acusaciones, pero sí hace que comparezca como testigo de cargo una prostituta.

La celda de la cárcel es el espacio más reducido que ocupa Isabel desde que llegó a Salamanca. Puesto que la falta de libertad y de espacio van siempre paralelos en la obra, cuando se reduce la una, disminuye también el otro. Es el momento más bajo para las aspiraciones de la joven. El entorno es igualmente negativo - los malos olores, la gota de agua, la soledad, los insultos de la guardia, el desaliento y suspiros de Luisa - Es la última prueba, de las muchas que ha tenido que superar la voluntad indomable de Isabel desde 
aquella noche en el espacio sin límites junto al río de Mozárbez. Pero, una vez más, la joven está a la altura de las circunstancias y no se asusta cuando Ruiz del Monte la interroga «en aquel lóbrego albergue del miedo» (Torres, 2010: 332). Y si, a pesar de su falta de experiencia, no la había atemorizado moverse por una ciudad alegre y bulliciosa, con matones disfrazados y prostíbulos que había conocido bien de la mano de Antonio, mucho menos iba a asustarla que el inquisidor usara ahora todo el entorno de aquella ciudad como testigo colectivo de supuestos crímenes. Isabel tiene fe en sí misma y eso le basta para estar segura de que la justicia de su idea será al fin reconocida por la justicia de la razón. Y puesto que se la acusa de haber matado a Laurentino Fresno, un crimen que no ha cometido, sabe que ella no es más que un pretexto para inculpar a Luisa de Medrano, como deduce cuando el inquisidor, fuera de sí una vez más, llama a Luisa «esa mujer de perdición». En su respuesta al inquisidor, Isabel usa entonces la palabra «muros» para darnos la imagen de Salamanca como una ciudad asediada porque guarda el único núcleo de libertad que queda en España, muros que intenta derribar un tirano irracional a quien ella no puede aceptar. «Sanad primero vuestra alma corrompida antes de ocuparos de cauterizar las heridas de los demás» (Torres, 2010: 334), le dice a Ruiz del Monte en su último encuentro antes del juicio, donde se enfrentarán en una contienda dialéctica las ideas de ambos bandos.

De la cárcel las rescata el maestrescuela, quien, tras una larga discusión con Antonio, sabe ya la identidad femenina de Isabel y, por su origen, algo más importante para él, que fue la razón por la que volvió a España: Isabel es su hija. Pero la salvación de las primas es momentánea porque será necesario resolver el conflicto de autoridad por voto en claustro universitario con todos los profesores presentes. Se juegan futuros y se juegan vidas. Como todas las acusaciones persiguen inculpar a Luisa de Medrano, su condición de hija de familia ilustre y de profesora no le da ninguna ventaja, pues sus propios colegas, como ella misma había manifestado a Isabel, eran contrarios a que una mujer ejerciera la cátedra. Pero como es norma en la novela, cada vez que se soluciona un misterio o se esclarece una identidad surge otro que enreda el argumento y mantiene la intriga. Así, sólo el maestrescuela está enterado de la verdadera identidad de Isabel porque es el único que sabe el secreto; sabe también que Antonio ha ido a Tordesillas para pedir ayuda al rey, lo que desconoce Ruiz del Monte. Por otro lado, éste ha descubierto ya la identidad judía del maestrescuela, y así se lo dice con una amenaza de muerte. Que las jóvenes se libren de la hoguera dependerá de la pericia al exponer acusación y defensa. Irónicamente, el futuro de la profesora de Oratoria está ahora en manos de los oradores. 
Los dos grupos se enfrentan en el pleno universitario para dirimir a cuál de ellos corresponde juzgar a Luisa de Medrano y al bachiller Pedro Bravo (Isabel de Vargas), acusados por el inquisidor Juan Ruiz del Monte de crímenes, inmoralidad, encubrimiento y varias otros delitos. El rector Maldonado tiene la palabra y, puesto que habla a todos los profesores, comienza por defender la integridad e independencia de la universidad, cuyas leyes han sido atacadas por el inquisidor cuando ordenó encarcelar a las jóvenes ignorando que esa era una competencia del maestrescuela. Los miembros del claustro de profesores deberán decidir no sólo si hay delito cometido por los acusados, sino también de un desafuero contra la autoridad universitaria por parte del inquisidor. Después, cede la palabra al maestrescuela.

La intervención del maestrescuela no es importante por lo que dice, sino por lo que siente. Es uno de los momentos más conmovedores de la obra. Como el único que sabe quién es de verdad Pedro Bravo, el maestrescuela se enfrenta con la necesidad de defender a tres identidades en una: Isabel de Vargas, Pedro Bravo (para todos los demás) y su hija. La vida de aquella niña que abandonó en un pueblo de Extremadura - cuando viajaba a Portugal tras la expulsión de 1492- para que una madre pudiera continuar la estirpe, dependía ahora de su habilidad para refutar las acusaciones de Ruiz del Monte. En 1492 fue requerido como cirujano para que ayudara a una parturienta a lograr su última esperanza de dar al marido un hijo. No lo pudo conseguir y le entregó a su propia hija, seguro de que así evitaría el sufrimiento de las dos. Sin saberlo, al salvar a Isabel y a su inesperada paciente aquel mes de julio de 1492, comenzó el primer trueque de identidades. Ahora, circunstancias otra vez inesperadas, ponían de nuevo en sus manos unas vidas. Era como otro parto difícil que le entregaba el destino a sabiendas de que la sentencia ya estaba decidida.

El maestrescuela expone que Pedro Bravo es acusado de unos crímenes que no ha cometido porque el inquisidor lo necesita para detener a Luisa de Medrano como encubridora. Varias otras personas pudieron cometer los crímenes, y da las razones. Pone su cargo en manos del claustro y pide se exima de toda culpa a los reos.

Cuando le toca el turno al inquisidor, acusa a Luisa de Medrano de toda clase de inmoralidades, y la animosidad del claustro contra la joven profesora le da la victoria por diecisiete votos contra cinco, pues a ninguno de los votantes «le importaba un comino la suerte de una mujer, Luisa, y de un simple bachiller de Medicina. Si el todopoderoso visitador real necesitaba de víctimas para calmar su ansia de sangre universitaria, que hincara sus dientes en ellos y dejara en paz al resto» (Torres, 2010: 364). Ni la ética ni las luces del 
claustro salmantino brillaban tanto como pudiera esperarse de la ciudad del saber. Tampoco los profesores eran lo que podía esperarse por su rango. Este episodio del juicio lo divide Torres en dos capítulos: el primero lo titula «El juicio de los hombres», donde vemos que es precisamente eso, juicio, lo que le falta al claustro de varones universitarios, y no puede considerarse como de justicia porque no tienen juicio los que juzgan. Se necesita otro capítulo, «La justicia del rey», para rebatir con pruebas las acusaciones falsas del falso justiciero Ruiz del Monte.

El inquisidor está dispuesto a llevarse a las dos jóvenes al suplicio para sacarles toda la verdad, cuando llega Antonio con el almirante de Castilla, Fadrique Enríquez, su padre. Traen un documento del rey Fernando por el que destituye de su cargo a Ruiz del Monte y nombra en su lugar a Fadrique. Ha de repetirse la votación porque el inquisidor no permitió que declararan los reos ni presentaran testigos y faltaba la firma del rector, indispensable según los estatutos de la universidad.

El inquisidor se había dejado llevar de nuevo por la soberbia ante la fácil victoria que intuía por la parcialidad del claustro. Esto le llevó a cometer dos errores graves. Aunque acusó a Luisa de Medrano de lascivia, inmoralidad y falta de respeto - por ser mujer - a la dignidad de las aulas universitarias, no tuvo ningún reparo en presentar ante el claustro como testigo de cargo a Gorgonia, la meretriz más famosa del barrio de la mancebía, la única persona que recurre al miedo como disculpa por no haber denunciado lo que dice haber visto. Ruiz del Monte es muy hábil para inventar identidades que no existen más que en su imaginación, pero muy torpe para descubrir las de su entorno. Por un deseo desmedido de acumular triunfos con víctimas y sin molestarse por hallar pruebas, acusa a Luisa de Medrano de posibles relaciones ilícitas con su pariente Pedro Bravo, y, como ignora la verdadera identidad de éste, se expone al ridículo porque, si necesario, la joven podrá descubrir la falsedad de sus acusaciones mostrando la verdad. Igualmente, como desconoce también quién es su incondicional Álvaro de San Emiliano, perderá toda credibilidad cuando lo descubra Antonio. Ruiz del Monte no estaba acostumbrado a probar sus sospechas porque se basaba en la rutina de una opinión aceptada por miedo. Pero los tiempos cambian, surgen nuevos modos y nuevos príncipes, adalides con fuerza e ingenio para instaurarlos.

Antonio Pimentel es el príncipe que viene a rescatar a su dama Oriana ${ }^{4}$. Llega en el momento preciso, con identidad ya esclarecida por su padre y

4. El Amadís de Gaula era el libro favorito de Antonio. Lo tiene en su lecho en el primer encuentro amoroso con Isabel, a quien llama su princesa Oriana. 
reconocida por el rey, que le ha nombrado conde de Beaufort. Como encargado que había sido por el maestrescuela de investigar los crímenes, es ahora testigo a favor de los reos. Tenía que ser él —no el rector ni el maestrescuelaporque Antonio es el elegido por Isabel, el primer fruto del enorme esfuerzo por autodefinirse y crear su futuro. Como tiene fe en sí misma, afronta el porvenir con ideas renovadoras y no arrastrando el pasado. Antonio es su príncipe, el que ella ha preferido sin que se lo imponga nadie, porque, como dijo cuando se conocieron, son almas gemelas. Todo el tiempo que estuvo en prisión, no dudó de que Antonio sería su único camino de salvación, porque había sido también hasta entonces su único maestro. Antonio va a terminar con el poder de un tirano, Ruiz del Monte, probando que «ninguna afirmación debe creerse solo (sic) porque nazca de autoridad» (Torres, 2010: 372, y «que cuando los que mandan pierden la vergüenza, los que obedecen olvidan el respeto» (Torres, 2010: 373). El joven descubre a los culpables, expone las intrigas de Ruiz del Monte por su ansia de poder y muestra que el dominico San Emiliano es culpable con Gorgonia de los crímenes de que se acusa a Pedro Bravo, y ha sido contagiado por ella con una enfermedad venérea que le tiene al borde de la muerte. Le quita la máscara a San Emiliano, aunque no descubre su verdadera identidad, y expone la estupidez de Ruiz del Monte. Éste no sabrá quién es en realidad su amigo hasta que esté ya próximo a morir a manos del gran maestre de la Garduña.

Isabel huyó de su hogar para no casarse con un hombre que no amaba y se había prometido que su porvenir sería obra de sí misma. Cuando halla el primer eslabón de ese futuro, Antonio, no permite que nadie la prive del hombre que quiere y, al final, ejecuta en pelea a Gorgonia y Álvaro de San Emiliano, maestre de la Garduña, por haber ordenado su muerte, lo que no deja lugar a dudas de que el valor, la destreza y el carácter del yo femenino de Isabel pueden emular el de cualquier hombre. El combate tiene lugar en campo abierto, con lo que termina la obra como empozó, con la muralla al fondo como recuerdo de la libertad que en ella se encierra y defiende. Cuando la joven tiene al hombre que ella eligió, abandona a Pedro Bravo para volver a ser Isabel de Vargas. La fe en sí misma y en la razón de su causa le da fuerza para mantener su idea contra tiempo y espacio, aunque tenga que emular también los métodos de los hombres porque, como había dicho Antonio, no se puede esperar respeto en los que obedecen cuando no hay vergüenza en los que mandan. Irónicamente, Isabel consigue como hombre el título universitario que deseaba como mujer porque así lo quieren ahora unos hombres a los que el ingenio y voluntad de la joven convencieron que existía de verdad un Pedro Bravo, el mismo que la pericia de su prima les indujo a aceptar como bachiller 
de Bolonia para que le concedieran reconocimiento legal en un diploma. La sutileza femenina se burla así de la arrogancia varonil. Isabel sigue siendo una mujer sin título y, al mismo tiempo, una mujer que lo tiene, aunque conseguido con una identidad falsa, porque, según el lema de los Reyes Católicos que ella repite para Antonio, tanto monta, monta tanto. Es decir, a despecho del prejuicio masculino, se ha otorgado un título legal a una identidad inexistente por la constancia y valor de una mujer de verdad con una identidad falsa. Dos ficciones que la lucha por la vida ha hecho se den en la misma persona: la hija de Judah Abravanel, maestrescuela de la Universidad de Salamanca.

\section{BIBLIOGRAFÍA}

TORRES, Margarita, La cátedra de la calavera, Madrid, Ediciones Planeta, 2010.

Fecha de recepción: 02/11/2011

Fecha de aceptación: 30-05-2012 